\title{
Pengaruh Experiental Marketing Terhadap Loyalitas Pelanggan Kebun Strawberry D'MOOAT
}

\author{
Virgin M. Manengkey \\ Tinneke M. Tumbel \\ Johnny A. F. Kalangi \\ Jurusan Ilmu Administrasi, Program Studi Administrasi Bisnis \\ Fakultas Ilmu Sosial dan Politik, Universitas Sam Ratulangi \\ virginmanengkey2@gmail.com
}

\begin{abstract}
This study aims to determine the experiential effect of marketing on customer loyalty at Strawberry D'Mooat Gardens. Experiential Marketing is a marketing approach that involves the emotions and feelings of consumers by creating positive experiences. Customer loyalty is a reliable measure to predict sales growth and customer loyalty can also be defined based on constitutional buying behavior. This study uses a quantitative approach, with a sample of 50 respondents who are customers of Strawberry D'Mooat Gardens who have visited more than twice. The sampling technique in this study is to use Simple Random Sampling. The data analysis method used in this study is a simple linear analysis method which includes validity test, reliability test, hypothesis test and analytical test of the coefficient of determination. It can be seen from the results of testing statistically it can be seen clearly that the independent variable Experiential Marketing affects the dependent variable Customer Loyalty. Based on the results of the study, it shows that experiential marketing has a positive and significant effect on customer loyalty. This shows that experiential marketing is one of the determinants of Customer Loyalty because good experiential marketing will create and maintain customer loyalty.
\end{abstract}

\section{Keywords: Experiential Marketing, Customer Loyalty}

\section{Pendahuluan}

Pemasaran merupakan usaha terpadu untuk menggabungkan rencana strategis yang diarahkan kepada usaha pemuasan kebutuhan dan keinginan konsumen melalui proses pertukaran atau transaksi. Kegiatan pemasaran harus dapat memberikan kepuasan kepada konsumen bila ingin mendapatkan tanggapan yang baik dari konsumen. Dalam menjalakan Kebun strawberry harus secara penuh bertanggung jawab tentang kepuasan produk yang ditawarkan tersebut. Dengan demikian segala aktivitas Kebun harus diarahkan untuk dapat memuaskan konsumen yang pada akhirnya bertujuan untuk memperoleh laba pada produk experiental marketing.

Konsep pemasaran yang memberikan pengalaman unik kepada pelanggan sudah dikenal dengan istilah experiential marketing. Konsep ini berusaha menghadirkan pengalaman yang unik, positif dan mengesankan kepada konsumen, dengan 
demikian konsumen akan merasa terkesan akan pengalaman selama menikmati produk dan keindahan alam dari Kebun strawberry ini akan tertanam dalam benak mereka, sehingga nantinya konsumen tidak hanya akan loyal tapi juga menyebarkan informasi mengenai produk dan keindahan Kebun strawberry ini. Dari waktu ke waktu konsep yang memberikan perhatian khusus terhadap pengalaman yang dialami konsumen ketika mengkonsumsi produk ini terus berkembang, dan semakin banyak juga perusahaan yang menerapkan konsep ini dalam menjalankan bisnisnya.

Loyalitas pelanggan yaitu kesetiaan dan hal tersebut sangat penting karena kesetiaan ini timbul tanpa adanya paksaan, tetapi timbul dari kesadaran sendiri. Seiring dengan berkembangnya zaman, persaingan dunia bisnis semakin ketat, banyak persaingan dengan kualitas terbaik bermunculan memperebutkan hati konsumen. Hal ini tentunya bertujuan untuk menguasai pangsa pasar masing-masing pada bidang usaha yang dijalankan. Mengacu pada kondisi saat ini maka digunakanlah suatu bentuk pemasaran yang mencoba menganalisis konsumen dengan menggunakan model-model psikologis (perilaku/mental) dalam menganalisis perilaku konsumen.

Lokasi Kebun strawberry berada di sekitar lahan hortikultura dengan didekorasi dan ditata dengan baik agar memiliki suasana yang lain sehingga dapat memberikan kesan tersendiri bagi setiap pengunjung yang datang. Kebun strawberry ini dikatakan unik karena satu-satunya tempat wisata yang identik dengan strawberry dan pemandangan indah dari sepadan danau mooat yang sangat menarik perhatian para wisatawan dan pengunjung lainnya. Kebun Strawberry merupakan tempat bersatai sekaligus tempat yang menawarkan produk makanan dan minuman dengan disertai nilai tambah berupa suasana yang muncul dan penataannya, sehingga pelanggan bukan hanya dipuaskan oleh produk yang mereka konsumsi, tetapi dari pengalaman yang mereka dapatkan dari awal mereka menjejakan kaki hingga mereka pulang.

Bisnis ini tidak sulit untuk mencari pelanggan bila dibandingkan dengan bisnis yang lain. Selain dalam pengelolaannya, pemilik bisa berbisnis sampingan seperti playground (tempat bermain anak-anak) dan cafe. Namun kondisi ini ditunjukkan dari respon para pengunjung yang kurang puas atas penerapan experiential marketing yang terdiri dari sense, feel, think, act dan relate. Dari hasil wawancara peneliti dengan konsumen, terdapat ketidakpuasan dimana karyawan masih kurang ramah dalam memberikan pelayanan serta tidak ada kedekatan secara emosional antara 
karyawan dan pengunjung. Apabila tidak menanggulangi masalah ini maka akan sangat berpengaruh bagi kebun strawberry yang nantinya akan mengalami penurunan pengunjung.

\section{Pemasaran}

Pemasaran adalah proses sosial dan manajerial dimana pribadi atau organisasi memperoleh apa yang mereka butuhkan dan inginkan melalui penciptaan dan pertukaran nilai dengan yang lain. Pemasaran merupakan suatu proses sosial yang didalamnya individu dan kelompok mendapatkan apa yang mereka butuhkan dan inginkan dengan menciptakan, menawarkan, dan secara bebas mempertukarkan produk yang bernilai dengan pihak lain. Menurut Kotler dalam Bisnarti Ayunda (2015).

\section{Experiental Marketing}

Experiential Marketing merupakan pendekatan pemasaran yang melibatkan emosi dan perasaan konsumen dengan menciptakan pengalaman-pengalaman positif yang tidak terlupakan sehingga konsumen mengkonsumsi dan fanatik terhadap produk tertentu. Menurut Schmitt dalam Nainggolan (2018). Sedangkan Menurut Kertajaya dalam Widiyanti (2018) experiental marketing adalah suatu konsep pemasaran yang bertujuan untuk membentuk pelanggan-pelanggan yang loyal dengan menyentuh emosi mereka dan memberikan suatu feeling yang positif terhadap produk dan service. Dengan adanya experiential marketing, pelanggan akan mampu membedakan produk dan jasa yang satu dengan lainnya karena mereka dapat merasakan dan memperoleh pengalaman secara langsung.

\section{Strategic Experiential Marketing}

Menurut Schmitt dalam Muhammad (2016) Suatu perusahaan dapat dikatakan bagus dalam menerapkan experiential marketing apabila telah memenuhi kriteria lima elemen atau strategi, yaitu:

1. Sense (Panca Indera) mempunyai ketertarikan dengan indra. Hal ini bertujuan untuk membuat pengalaman sensorik melalui penglihatan, suara, sentuhan, rasa dan penciuman. Sense marketing dapat dipakai untuk membedakan perusahaan dan produk, motivasi kepada konsumen, dan nilai produk menjadi bertambah.

2. Feel (Perasaan) yaitu membangkitkan perasaan dan emosi pelanggan yang bertujuan menciptakan pengalaman afektif dari suasana hati positif berkaitan dengan merek sampai emosi yang kuat dari kegembiraan dan kebanggaan. 
3. Think (Pola Pikir) yaitu menarik kecerdasan yang bertujuan untuk menciptakan kognitif, pengalaman pemecahan masalah yang menyangkut konsumen secara kreatif. Think membuat pelanggan untuk berfikir memusat dan menyebar melalui kejutan, intrik, dan provokasi.

4. Act (Perilaku) yaitu memiliki tujuan untuk mempengaruhi pengalaman tubuh, gaya hidup dan juga interaksi. Act marketing menjadikan kehidupan konsumen dengan meningkatkan pengalaman fisik mereka, menunjukkan pada pelanggan cara lain untuk melaksanakan aktivitas, gaya hidup alternatif dan interaksi.

5. Relate (Pertalian) yaitu memuat tentang aspek pemasaran sense, feel, think dan act. Namun, relate marketing tumbuh melampaui kepribadian individu, perasaan pribadi, hal tersebut membuat pengalaman individu bertambah dan menghubungkan individu tersebut dengan dirinya sendiri, orang lain ataupun budaya.

\section{Loyalitas Pelanggan}

Loyalitas pelanggan secara umum dapat diartikan sebagai kesetiaan seseorang atas suatu produk, baik barang atau jasa tertentu. Loyalitas pelanggan merupakan kelanjutan dari kepuasan pelanggan dalam menggunakan fasilitas maupun jasa pelayanan yang diberikan oleh pihak perusahaan, serta untuk tetap manjadi pelanggan dari perusahaan tersebut.

Loyalitas pelanggan merupakan ukuran yang dapat diandalkan untuk memprediksi pertumbuhan penjualan dan loyalitas pelanggan juga dapat didefinisikan berdasarkan perilaku pembelian yang konstiten.

Menurut Griffin (2015). Loyalitas sebagai kondisi dimana pelanggan mempunyai sikap positif terhadap suatu merek, mempunyai komitmen pada merek tersebut dan bermaksud meneruskan pembeliannya di masa mendatang. Menurut Mowen dan Minor dalam oktafialia (2015).

\section{Karakteristik Loyalitas Pelanggan}

Hal tersebut diperkuat dengan pernyataan dari Griffin dalam Nurwidayat (2015), yang menyatakan bahwa karakteristik pelanggan yang loyal antara lain:

1. Melakukan pembelian berulang secara teratur.

2. Membeli antar lini produk dan jasa.

3. Menunjukkan kekebalan terhadap tarikan dari pesaing

4. Mereferensikan kepada orang lain 


\section{Motode Penelitian}

Dalam penelitian yang di lakukan pada Kebun Strawberry D’Mooat, penulis menggunakan metode kuantitatif deskriptif. Popilasi dalam penelitian ini adalah pengunjung Kebun Strawberry D’Mooat yang tidak diketahui jumlah populasi pastinya. Sampelnya berjumlah 50 responden karena banyaknya keterbatasan dalam melakukan peneltian, dan Teknik yang digunakan untuk menentukan sampel yaitu berdasarkan Roscoe dalam Sugiyono (2017) menyarankan untuk ukuran sampel yang layak dalam penelitian yaitu lebih besar dari 30 dan kurang dari 500. Teknik pengumpulan data yaitu kuesioner yang dinilai menggunakan Skala Likert dan model analisis yang digunakan yaitu analisis linier sederhana.

\section{Hasil Penelitian}

Hasil yang didapatkan sesuai hasil yang diuji menggunakan SPSS versi 25.00 for windows menyatakan bahwa semua pernyataan pada kuesioner dinyatakan valid karena hasil yang di dapati bahwa experiental marketing dan loyalitas pelanggan semua item pernyataan memiliki nilai signifikansi lebih kecil dari 0.05 yaitu 0,000. Berdasarkan hasil uji validitas suatu alat ukur akan dikatakan valid apabila memiliki nilai koefisien validitas yang lebih besar dari angka yang telah ditentukan yaitu 0,279. data diperoleh dari 10 item pernyataan variabel Experiental Marketing dan 4 item pertanyaan Loyalitas Pelanggan yang menunjukan bahwa nilai Rhitung lebih besar dari nilai Rtabel sehingga dapat disimpulkan bahwa pada uji validitas dinyatakan valid atau dapat digunakan sebagai penelitian.

Hasil uji reliabilitas di peroleh nilai Cronbach alpha variable Experiental Marketing 0,754>0,60 sehingga dapat dinyatakan bahwa variabel Experiental Marketing diterima atau reliabel. Sedangkan variabel Loyalitas Pelanggan memperoleh nilai Cronbach alpha Variabel Loyalitas Pelanggan 0,781>0,60 sehingga dapat dinyatakan bahwa variabel Loyalitas Pelanggan dinyatakan diterima atau reliabel. Maka kedua variabel tersebut dapat digunakan sebagai data penelitian.

Berdasarkan hasil data analisis linier sederhana yang diperoleh diketahui bahwa experiental marketing berpengaruh positif terhadap loyalitas pelanggan. Nilai Constant 6.881 sedangkan nilai Experiental Marketing sebesar $0.250 \quad$ sehingga persamaan regresi linear sederhana dapat ditulis $\mathrm{Y}=6.881+0.250$. Persamaan tersebut dapat dijelaskan bahwa nilai konstiten variable Loyalitas Pelanggan adalah sebesar 6.881, Sedangkan koefisien regresi Experiental Marketing sebesar 0,250 menyatakan bahwa koefisien regresi 
tersebut bernilai positif sehingga dapat dikatakan bahwa arah pengaruh variabel Experiental Marketing terhadap Loyalitas Pelanggan adalah positive.

Berdasarkan perhitungan koefisien bahwa besarnya nilai $\mathrm{R}$ Square yaitu sebesar 0.385 berarti mempunyai kontribusi sebesar $38,5 \%$ yang menyatakan variable Experintal Marketing dipengaruhi oleh variable Loyalitas Pelanggan, sedangkan sisanya sebesar $61,5 \%$ dipengaruhi oleh faktor lai yang tidak masuk dalam penelitian ini.

\section{Pembahasan}

Hasil dari penelitan ini menyatakan bahwa experiental marketing mempunyai pengaruh terhadap loyalitas pelanggan. Dimana berdasarkan hasil dari penelitian yang telah dilakukan menunjukan bahwa experiental marketing mempunyai pengaruh signifikan terhadap loyalitas pelanggan. Pengaruh experiential marketing terhadap loyalitas pelanggan kebun strawberry d'mooat ditunjukkan dengan adanya desain interior kebun strawberry dan sensasi kesejukkan alam yang menurut pelanggan ini merupakan hal yang cukup menarik serta adanya kebun strawberry dan playground, dapat memberikan kepuasan dan kesenangan bagi para pelanggan. Experiential Marketing merupakan pendekatan pemasaran yang melibatkan emosi dan perasaan konsumen dengan menciptakan pengalamanpengalaman positif yang tidak terlupakan. Dengan adanya experiential marketing, pelanggan akan mampu membedakan produk dan jasa yang satu dengan lainnya karena mereka dapat merasakan dan memperoleh pengalaman secara langsung. Menurut Schmitt dalam Nainggolan (2018).

Dengan demikian dapat dikatakan bahwa dengan adanya perubahan experiential marketing maka dengan sendirinya akan terjadi pada perubahan loyalitas pelanggan. Loyalitas atau kesetiaan didefinisikan sebagai komitmen yang dipegang kuat untuk membeli atau berlangganan lagi produk atau jasa tertentu di masa depan meskipun ada pengaruh situasi dan usaha pemasaran yang berpotensi menyebabkan perubahan perilaku. Menurut Kotler dan Keller dalam Oktafalia (2015).

Hasil penelitian ini mendukung penelitian yang sudah pernah dilakukan oleh Muhammad Rizal (2016) dengan judul "Pengaruh Experiential Marketing terhadap Loyalitas Pelanggan Kolam Renang Mutiara Waterpark Perumnas Langsa", yang menyimpulkan bahwa hasil penelitian ini membuktikan bahwa experiential marketing berpengaruh signifikan terhadap loyalitas pelanggan kolam renang Mutiara Waterpark Perumnas Langsa. 
Dari hasil statistic tersebut dapat dilihat dengan jelas bahwa variable experiental marketing atau variable bebas berpengaruh terhadap variable loyalitas pelanggan atau variable terikat. Pengaruh yang diberikan variable bebas tersebut bersifat positif yang berarti semakin akrif experiental marketing maka mengakibatkan semakin tinggi juga loyalitas pelanggan yang akan dihasilkan. Hal ini dapat menunjukan bahwa experiental marketing merupakan salah satu penentu loyalitas pelanggan karena experiental marketing yang baik akan menciptakan dan akan mempertahankan loyalitas pelanggan. Jadi semakin tinggi experiental marketing yang diterapkan maka akan meningkatkan loyalitas pelanggan.

\section{Kesimpulan}

Hasil penelitian membuktikan bahwa variabel Experiental Marketing berpengaruh positif dan signifikan terhadap Loyalitas Pelanggan Kebun Strawberry D'Mooat. Hal ini dikarenakan bahwa dengan adanya Experiental Marketing yang baik dan fasilitas dan pemandangan yang indah akan membuat pelanggan merasa lebih loyal pada Kebun Strawberry D’Mooat tersebut.

Berdasarkan hasil data analisis linier sederhana pada penelitian ini diketahui experiental marketing dan loyalitas pelang- gan Kebun Strawberry D'Mooat menyatakan koefisien bernilai positif sehingga dapat dikatakan bahwa arah pengaruh variabel Experiental Marketing terhadap Loyalitas Pelanggan adalah positif. Dimana ketika experiental marketing itu di iformasikan ke konsumen, maka konsumen akan tetap melakukan kunjungan secara berulang dan mereka akan merekomendasi serta menyebarkan hal-hal positif terhadap calon konsumen Kebun Strawberry D’Mooat.

Hasil penelitian membuktikan bahwa koefisien determinan yang diperoleh dapat diketahui bahwa besarnya nilai $\mathrm{R}$ Square yaitu sebesar 0.385 berarti mempunyai kontribusi sebesar 38,5\% yang menyatakan variable Experintal Marketing (X) dipengaruhi oleh variable Loyalitas Pelanggan (Y), sedangkan sisanya sebesar $61,5 \%$ dipengaruhi oleh faktor lain yang tidak masuk dalam penelitian ini.

\section{Saran}

Kebun Strawberry D'Mooat sekiranya dapat meningkatkan pelayanan yang lebih baik dan menarik sehingga bisa menyenangan setiap konsumen yang datang dan lebih memiliki loyalitas yang tinggi terhadap Kebun Strawberry D'Mooat. Kebun Strawberry D'Mooat harus lebih mendalami dan lebih serius untuk menjalani hubungan dengan para konsumen 
and Behavioral Studies, Oktober

agar experiental marketing yang dijalani semakin erat serta lebih banyak inovasiinovasi baru agar dapat memperindah lokasi tersebut. Kebun Strawberry D’Mooat sekiranya mampu mempertahankan dan meningkatkan penerapan experiental marketing, baik dalam kepercayaan maupun dalam pelayanan. Komitmen yang dibuat, komunikasi yang dijalani, sehingga dapat memberikan kepuasan bagi konsumen yang berkunjung.

\section{Daftar Pustaka}

Bisnarti Ayunda, 2015, Pengaruh Experiential Marketing Terhadap Loyalitas Pelanggan (The Effect Of Experiental Marketing On Customer Loyalty) jurnal Digest Marketing. 1(1) : 51

Kotler Philip dan Keller Kevin Lane, 2017, Manajemen Pemasaran jilid 1, Penerjemah Benyamin Molan. New Jersey, PT INDEKS

Muhammad Rizal, 2016, Pengaruh Experiential Marketing terhadap Loyalitas Pelanggan Kolam Renang Mutiara Waterpark Perumnas Langsa, Jurnal Manajemen Dan Keuangan. 5 (1) : 472

Nainggolan Nadya Astari, 2018, Analisis Pengaruh Experiential Marketing Terhadap Loyalitas Pelanggan (Studi pada Pelanggan Doodle Bar Medan), Departemen Administrasi Bisnis 2018 : 34

Oktafalia Marisa, Janny Rowena, 2017, Pengaruh Experiential Marketing Terhadap Loyalitas Konsumen, jurnal Conference on Management
2017

Wiwik Widiyanti dan Julia Retnowulan, 2018, Pengaruh Experiental Marketing Terhadap Loyalitas Pengunjung Taman Wisata Edukasi D'Kandang Depok, Jurnal Ecodemica, 2 (1) : 65 